\title{
New tricks for old dogs
}

\author{
James Jaggers, MD
}

\footnotetext{
From the Division of Thoracic Surgery, University of Colorado; the Divisions of Pediatric Cardiac Surgery and Congenital Cardiac Surgery, Childrens Hospital Colorado, Aurora, Colo.

Disclosures: Author has nothing to disclose with regard to commercial support.

Received for publication Jan 31, 2017; accepted for publication Jan 31, 2017; available ahead of print March 7 , 2017.

Address for reprints: James Jaggers, MD, Professor of Surgery, Division of Thoracic Surgery, University of Colorado, Barton Elliman Chair of Pediatric Cardiac Surgery, Chief of Congenital Cardiac Surgery, Childrens Hospital Colorado, 13123 East 16th St., Aurora, Colorado 80045 (E-mail: james.jaggers@ childrenscolorado.org). J Thorac Cardiovasc Surg 2017;153:1153-4 $0022-5223 / \$ 36.00$

Copyright $(2017$ by The American Association for Thoracic Surgery http://dx.doi.org/10.1016/j.jtcvs.2017.01.038
}

The arterial switch procedure, originally described by Jatene and colleagues ${ }^{1}$ in 1976 and quickly adopted by Castenada and associates ${ }^{2}$ at Boston Children's Hospital, has become one of the great success stories in congenital cardiac surgery. Surgical and long-term outcomes are excellent. $^{3}$ The technical aspects of the operation have not varied significantly in the last 25 years. But just when you thought there was nothing new under the sun, along comes an innovative new technique that on the surface seems so obvious, you can't understand why someone else hasn't thought of it before.

In their case report in this issue of the Journal, Ko and coauthors ${ }^{4}$ report a case of a neonate with transposition of the great arteries, intact ventricular septum, and a single coronary artery (sinus 1: left anterior descending coronary artery, circumflex artery, right coronary artery) without an intramural segment. Although it is not specifically described, we probably should assume that the coronary orifice was in the center of the sinus without an intramural in course. In this pattern, the right coronary artery travels anterior to aorta to reach the atrioventricular groove. This is the second most common type of single coronary artery associated with transposition of the great arteries (with the first being sinus 2: left anterior descending coronary artery, circumflex artery, right coronary artery, with the left main coronary artery traveling posterior to the pulmonary artery). ${ }^{1}$ Arterial switch operation with a single coronary artery has been associated with increased risk of mortality, but in most recent series there appears to be no increase with current surgical methods. If the coronary button anastomosis is under stretch, there can be compression or kinking of the coronary artery that may be made worse by compression by the neopulmonary outflow tract, resulting in ischemia in the early perioperative period.

The challenge in the transfer of this type of single coronary artery is that the button of the coronary artery is rotated $180^{\circ}$ to the course of the right coronary artery, which can result in stretch or distortion of the right coronary ostia. In general, simple mobilization of the proximal right coronary artery will result in enough mobility for safe transfer of

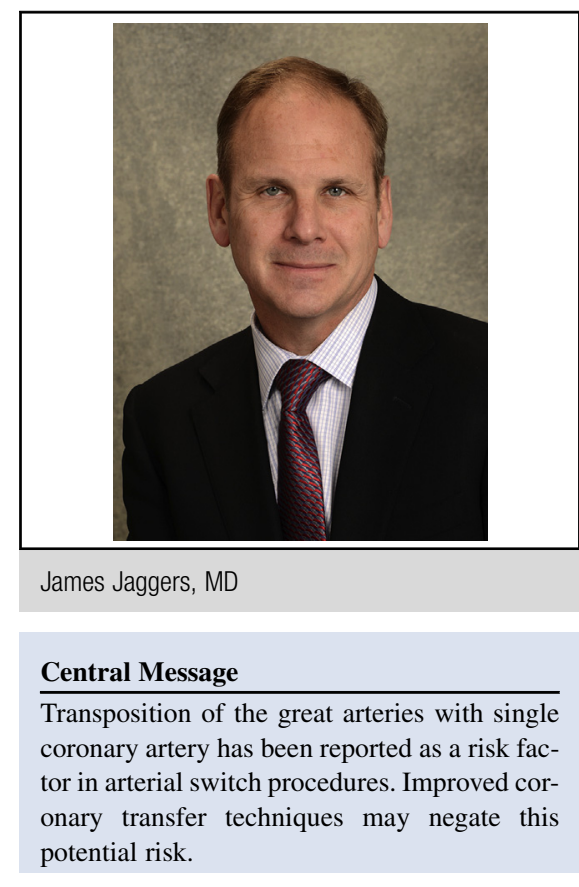

See Article page 1150 .

the coronary artery. In some situations, the ostium may be further away from the target in the neoaorta, however, and undue tension results. Several techniques have been described to deal with this. Most have been designed to extend the coronary button to relieve tension.

The technique described in this report is innovative; however, one should consider the 3-dimensional aspect. As this technique is described, the axis of rotation of the coronary button is no different from the usual transfer rotation. This technique can extend the button, although not as much as with other techniques that involve extending the coronary artery with a tube of pericardial or prosthetic material. One can imagine that with this technique, even a slight rotation of the coronary artery could result in kinking of either right or left coronary artery. It does have the advantage of avoiding prosthetic or autologous pericardial tissue. As with any techniques of coronary artery transfer, great care must be taken to not place the coronary artery too low into the neoaortic sinus.

To paraphrase a quote attributed to Albert Szent-Györgyi, the scientist who discovered vitamin C: Innovation is seeing what everyone else has seen and thinking and doing what no one else has done. Ko and his coauthors ${ }^{4}$ are to be congratulated for seeing this common problem and thinking and doing what other have not. We look forward to seeing 
further reports from this group for the outcomes of the technique.

\section{References}

1. Jatene AD, Fontes VF, Paulista PP, Souza LC, Neger F, Galantier M, et al. Anatomic correction of transposition of the great vessels. J Thorac Cardiovasc Surg. 1976;72:364-70.
2. Castaneda AR, Norwood WI, Jonas RA, Colan SD, Sanders SP, Lang P. Transposition of the great arteries and intact ventricular septum: anatomical repair in the neonate. Ann Thorac Surg. 1984;38:438-43.

3. Scheule AM, Zurakowski D, Blume ED, Stamm C, del Nido PJ, Mayer JE Jr, et al. Arterial switch operation with a single coronary artery. J Thorac Cardiovasc Surg. 2002; 123:1164-72.

4. Ko Y, Nomura K, Nakao M. New coronary transfer technique for transposition of the great arteries with a single coronary artery. J Thorac Cardiovasc Surg. 2017; 153:1150-2. 